\title{
Effect of solar and magnetic activity on VHF scintillations near the equatorial anomaly crest
}

\author{
R. P. Singh ${ }^{1}$, R. P. Patel ${ }^{1}$, and A. K. Singh ${ }^{2}$ \\ ${ }^{1}$ Atmospheric Research Laboratory, Physics Department, Banaras Hindu University, Varanasi-221 005, India \\ ${ }^{2}$ Department of Physics, Maharaja College, VKS University, Arrah-802 301, Bihar, India
}

Received: 11 October 2003 - Revised: 4 May 2004 - Accepted: 18 May 2004 - Published: 7 September 2004

\begin{abstract}
The VHF amplitude scintillation recorded during the period January 1991 to December 1993 in the declining phase of a solar cycle and April 1998 to December 1999 in the ascending phase of the next solar cycle at Varanasi (geogr. lat. $=25.3^{\circ}$, long. $=83.0^{\circ}$, dip $=37^{\circ} \mathrm{N}$ ) have been analyzed to study the behavior of ionospheric irregularities during active solar periods and magnetic storms. It is shown that irregularities occur at arbitrary times and may last for $<30 \mathrm{~min}$. A rise in solar activity increases scintillations during winter (November-February) and near equinoxes (March-April; September-October), whereas it depresses the scintillations during the summer (May-July). In general, the role of magnetic activity is to suppress scintillations in the pre-midnight period and to increase it in the post-midnight period during equinox and winter seasons, whilst during summer months the effect is reversed. The pre-midnight scintillation is sometimes observed when the main phase of $D_{s t}$ corresponds to the pre-midnight period. The annual variation shows suppression of scintillations on disturbed days, both during premidnight and post-midnight period, which becomes more effective during years of high solar activity. It is observed that for magnetic storms for which the recovery phase starts postmidnight, the probability of occurrence of irregularities is enhanced during this time. If the magnetic storm occurred during daytime, then the probability of occurrence of scintillations during the night hours is decreased. The penetration of magnetospheric electric fields to the magnetic equator affects the evolution of low-latitude irregularities. A delayed disturbance dynamo electric field also affects the development of irregularities.
\end{abstract}

Key words. Ionosphere (ionospheric irregularities; equatorial ionosphere) - Radio science (ionospheric propagation)

\section{Introduction}

The space-time variability of ionospheric irregularities are of serious concern to radio communications because these

Correspondence to: R. P. Singh

(rampal@banaras.ernet.in) irregularities affect the amplitude and phase of satellite signals. Amplitude variations may induce signal fading, and when depth of fading exceeds the fade margin of a receiving system, message errors are encountered. If navigation is dependent on the Global Positioning System (GPS), then amplitude fluctuations may lead to data loss and cycle slips (Aarons and Basu, 1994). Sudden phase changes may cause a loss of phase lock in GPS receivers (Basu et al., 1995). Equatorial scintillations during a high solar activity period have been found to be sufficiently intense to disable many communication and navigation systems (Groves et al., 1997). Hence, it is necessary to understand the role of space-weather events on scintillations.

The fluctuations in the ionospheric electron density, commonly known as irregularities, are generated on the bottom side of the post-sunset F-region over the magnetic equator by the nonlinear Rayleigh-Taylor instability mechanism. Irregularities are of two types, namely those related to plasma bubbles (Ossakow,1981; Kelley, 1989) and those known as bottom side sinusoidal irregularities (Valladares et al., 1983). The plasma bubbles become highly structured as they rise to higher altitudes above the magnetic equator. These bubbles then move along the geomagnetic field to anomaly locations of $15^{\circ} \mathrm{N}$ and $15^{\circ} \mathrm{S}$ magnetic latitudes (Groves et al., 1997). The electric field at the site plays a dominant role in shaping the development of these irregularities. The field is eastward during the day and is westward after sunset. Before this direction reversal, there is a sudden enhancement of the eastward electric field (Fejer, 1991, 1997; Hari et al., 1996). The field and its variation is season and solar activity dependent. Any change in the electric field influences the occurrence of low-latitude scintillations. With increasing interest in understanding the behavior of ionospheric irregularities near the magnetic equator, efforts have been made to examine the influence of solar and magnetic activity over the occurrence of scintillations associated with ionospheric irregularities (Aarons et al., 1980; Rastogi et al., 1981; DasGupta et al., 1985; Dabas et al., 1989; Pathak et al., 1995; Chakraborty et al., 1999; Kumar and Gwal, 2000; Banola et al., 2001; Basu et al., 2001a, b; Bhattacharya et al., 2002). Analysis of the role of magnetic storms on low-latitude scintillations 
VARANASI, 1991-1999.

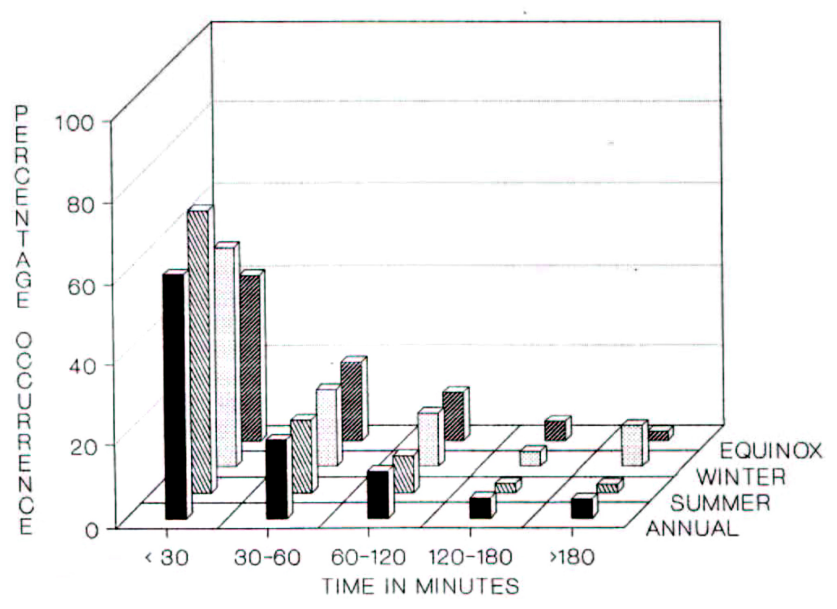

Fig. 1. Percentage occurrence of patch duration is given for different seasons of 1991-1993 and 1998-1999. The mean values of patch duration in the summer, winter and equinox seasons are 23, 34 and $36 \mathrm{~min}$, respectively.

has shown that for most of the storms for which the recovery phase starts after midnight, the probability of occurrence of scintillation activity is enhanced during the post-midnight period (Aarons and Das Gupta, 1984; Kumar and Gwal, 2000). These results have been interpreted in terms of the reversal of the equatorial horizontal electric field (DasGupta et al., 1985). It has also been reported that during certain periods of high solar and geomagnetic activity scintillations are suppressed (Koster, 1972; Chandra and Rastogi, 1974; Vyas and Chandra, 1994; Banola et al., 2001). The penetration of the magnetospheric electric field during the storm and the disturbance dynamo electric fields together control the evolution of equatorial F-region irregularities (Fejer et al., 1999; Basu et al., 2001a, b). An enhancement in the eastward electric field raises the F-layer at the magnetic equator to higher altitudes where conditions more favorable for the generation of irregularities may be obtained (Haerendel, 1974; Woodman and LaHoz, 1976).

In this paper, we present some results of $244-\mathrm{MHz}$ amplitude scintillation measurements during the period January 1991 to December 1993 in the declining phase of the solar cycle and during April 1998 to December 1999 in the ascending phase of the succeeding solar cycle at Varanasi, which is situated near the northern crest of the equatorial anomaly zone. We have examined the seasonal variation of the scintillation activity and showed that both the seasonal pattern and the level of scintillations are controlled by solar activity. The effect of magnetic activity on the occurrence of scintillations is also studied. Finally, the effect of magnetic storms is also discussed using the $D_{s t}$ index .

\section{Data}

The amplitude scintillations of the 244-MHz signal radiated from the geostationary satellite FLEETSAT situated at $73^{\circ} \mathrm{E}$ longitude were continuously monitored at Varanasi using a fixed frequency VHF receiver and strip chart recorder. The receiver was calibrated using the method described by Basu and Basu (1989). The dynamic range of the receiver was about $20 \mathrm{~dB}$. Most of our scintillation data were recorded on a strip chart which is calibrated as $1 \mathrm{~cm}$ equal to $2.54 \mathrm{~dB}$. In addition to the normal chart recorder, data were also recorded digitally, at the sampling rate of $10 \mathrm{~Hz}$, on a few nights. The amplitude fluctuations having peak-to-peak variations greater than $1 \mathrm{~dB}$ were included in the present analysis using night time data. The scintillation index in $\mathrm{dB}$ has been scaled manually every $15 \mathrm{~min}$ by measuring peak-to-peak $\mathrm{P}_{\max }-\mathrm{P}_{\min }$ excursion in $\mathrm{dB}$ and using a calibration chart and a conversion chart (Whitney et al., 1969), where $\mathrm{P}_{\max }$ is the power amplitude of the third peak down from the maximum excursion and $\mathrm{P}_{\min }$ is the power amplitude of the third level up from the minimum excursion. The scintillation data are tabulated for each $15 \mathrm{~min}$, to count the number of events per hour and hence to evaluate the occurrence rate. The percentage occurrence of scintillations has been calculated after dividing the number of the occurrence of scintillation data by total number of days of scintillation recorded and then multiplying by 100 .

In the analysis, we have used data from the nearest available station, Ahmedabad (geogr. lat. $=23.1^{\circ} \mathrm{N}$, long. $\left.=72.3^{\circ} \mathrm{E}, \operatorname{dip}=34^{\circ} \mathrm{N}\right)$, for the height rise of $\mathrm{F}$ layer $\left(\mathrm{h}^{\prime} \mathrm{F}\right)$ and have studied the dependence of scintillation on $\mathrm{h}^{\prime} \mathrm{F}$. A total of 50 geomagnetic storms during the above period are included, and the results of these studies are presented. We have tried to illustrate the results using some selected cases.

\section{Results and discussions}

\subsection{General features}

Scintillations occur at irregular intervals and last for a short while (<30 min) at Varanasi (Singh et al., 1993, 1997). Using the data for the years 1991-1993 and 1998-1999, the distribution of their duration in winter, summer and at the equinoxes is shown in Fig. 1, along with the annual variation. The mean values for the duration of these scintillations are 34, 23 and $36 \mathrm{~min}$ in winter, summer and equinox seasons respectively. The intensity distribution in the scintillations observed during the above period is shown in Fig. 2. Different hatching indicates fade depth indices in $\mathrm{dB}$ ranging from $1 \mathrm{~dB}$ to $20 \mathrm{~dB}$. Fade depth during the summer months is usually less than $5 \mathrm{~dB}$, whereas during the winter and equinox months, it varies between 5 and $15 \mathrm{~dB}$. Fade depths greater than $15 \mathrm{~dB}$ were observed in April and October 1991 (Singh and Singh, 1997) and were more frequent during 1998 and 1999. Chandra et al. (1993) have analyzed scintillation data recorded at a chain of stations covering the whole of India 
VARANASI, 1991-1999

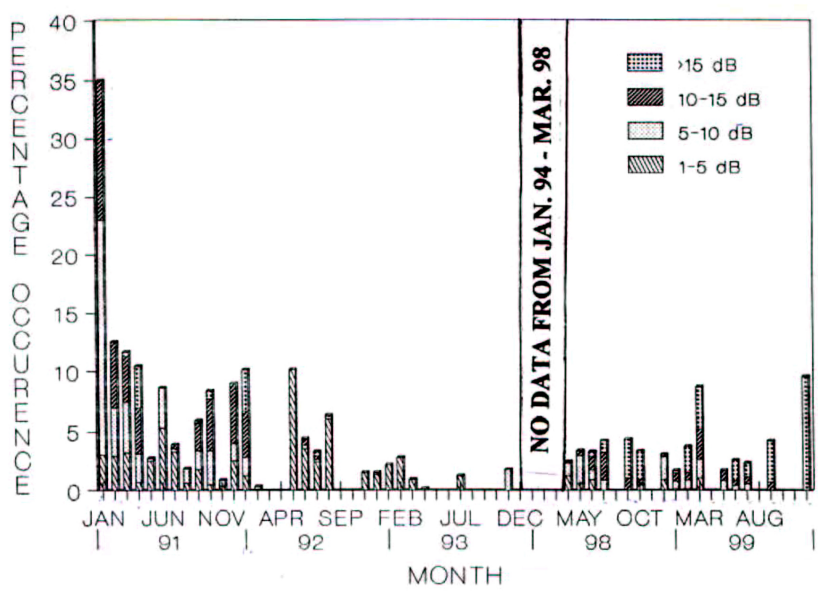

Fig. 2. Percentage occurrence of 15-min fade depth indices (in $\mathrm{dB}$ ) for nighttime scintillation is given in the figure. The length of the hatching shows the percentage occurrence. For example, in January 1991, the occurrence of scintillations having a fade depth between 10 and $15 \mathrm{~dB}$ is $(35-23=12) 12 \%$.

\section{VARANASI, 1991-1999}

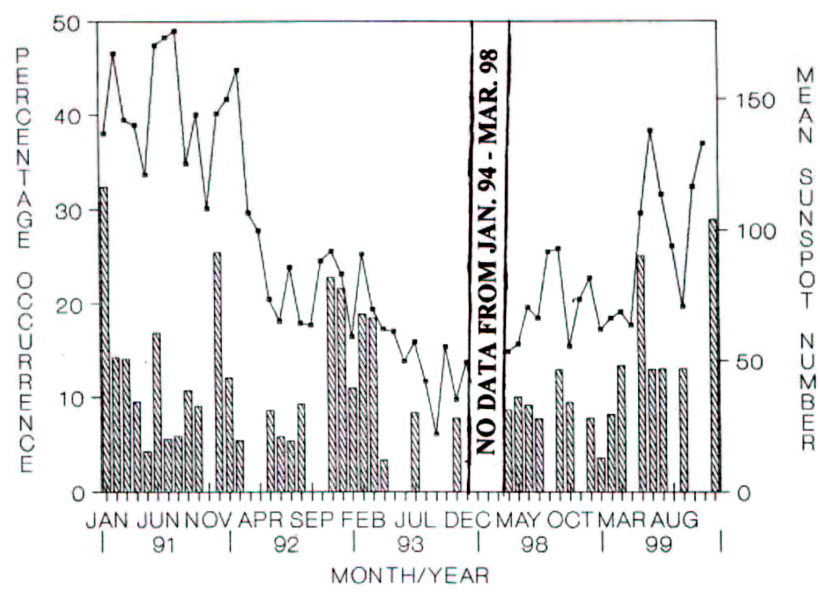

Fig. 3. The month-to-month variation of the mean percentage occurrence of scintillations and sun spot numbers for the years January 1991-December 1993 and April 1998-December 1999 are shown.

and have shown that the duration of the scintillations becomes greater as one approaches the equator. This time duration represents the east-west dimension of the irregularity (Mathew et al., 1992). The relatively intense and faster fade rate observed before midnight at Varanasi could be of equatorial origin during winter and equinox seasons (Pathan et al., 1992; Kumar and Gwal, 2000). Comparatively weak, slow and short duration scintillations seen during summer could have a local/mid-latitude/equatorial origin (Das Gupta et al., 1981; Chakraborty et al., 1999).

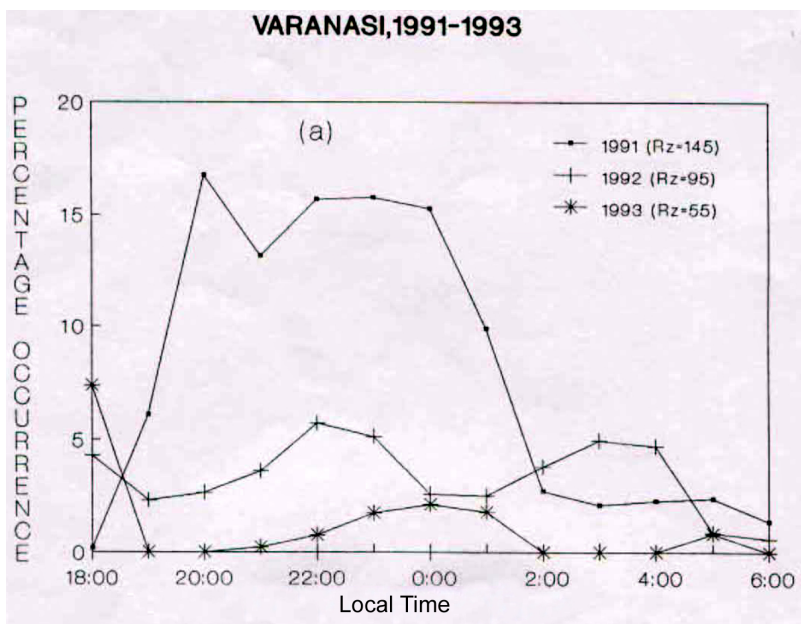

VARANASI,1998-1999

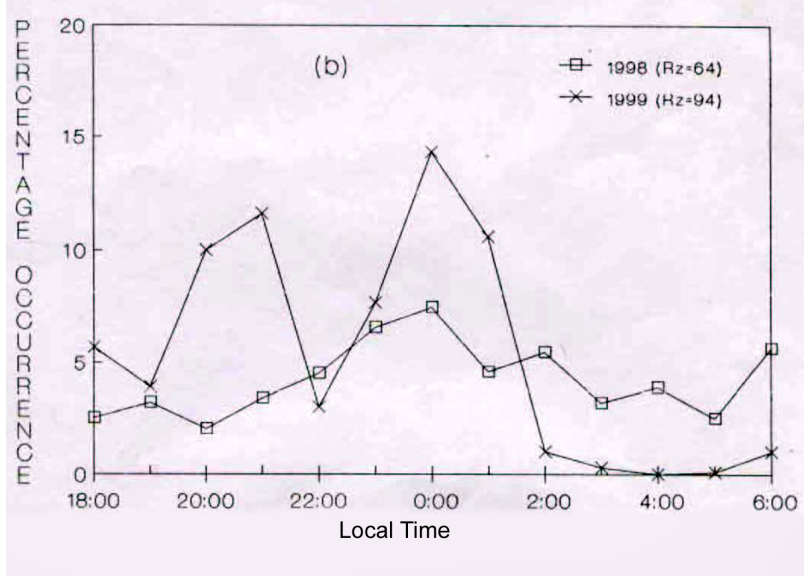

Fig. 4. The nocturnal variation of scintillation occurrence rate along with mean sun spot number as a function of time is shown (a) peak scintillation occurrence 17\% during 1991 ( $\mathrm{Rz}=145), 6 \%$ during $1992(\mathrm{Rz}=95)$ and 3\% during $1993(\mathrm{Rz}=55)$ (b) 7.5\% during $1998(\mathrm{Rz}=64)$ and $15 \%$ during $1999(\mathrm{Rz}=94)$, where $\mathrm{Rz}$ is mean sunspot number.

\subsection{Effect of solar activity}

The sunspot number is considered to be a measure of solar activity. Figure 3 shows the month-to-month variation of the mean percentage occurrence of scintillations and the sunspot numbers for the years 1991-1993 and 1998-1999. No data is available for January 1994-March 1998. During equinox and winter months, scintillation activity increased with increased sunspot numbers, whereas during the summer months no significant change in the occurrence of scintillations is seen with a change in solar activity. Further, although, the scintillation activity changed with solar activity, the equinoctial maxima were always most prominent every year during 1991 to 1999 . The solar activity effects reported here are consistent with previous results reported from studies at anomaly crest stations (Pathak et al., 1995; Kumar and Gwal, 2000). 
VARANASI, 1991-1999.

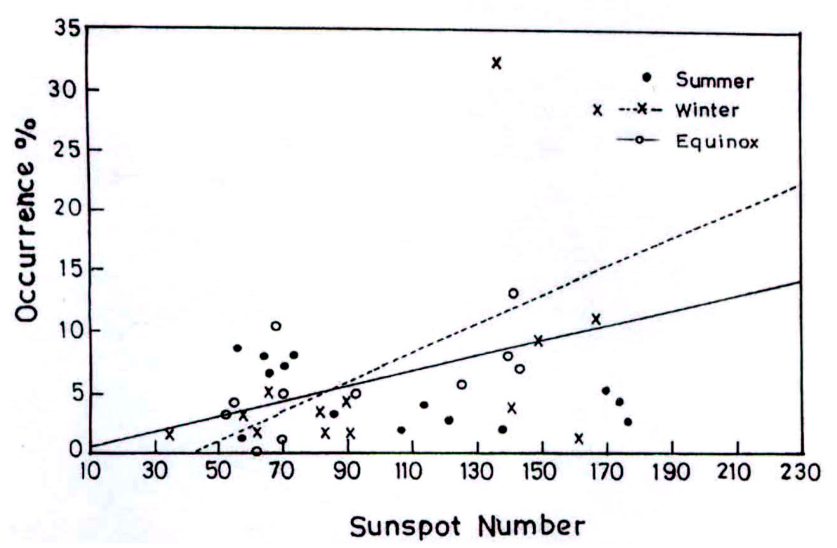

Fig. 5. Variation in scintillation occurrence rate with mean sunspot number for different seasons (summer, winter and equinox) during the years 1991-1999 is shown.

The nocturnal variation of the scintillation occurrence rate, along with mean sunspot numbers (Rz) is shown in Fig. 4. The data show two peaks, a familiar one early in the night at about 20:00 LT and another less recognized one, near midnight. The peak of scintillation occurrence rate was $17 \%$ during $1991(\mathrm{Rz}=145), 6 \%$ during $1992(\mathrm{Rz}=95)$ and 3\% during $1993(\mathrm{Rz}=55)$, which shows that the scintillation activity decreases with a decrease in solar activity. Similar variations have been seen at Bhopal (Kumar and Gwal, 2000) and at Rajkot (Pathak et al., 1995). Increase in scintillation activity with an increase in solar activity is also evident from the data taken during $1998(\mathrm{Rz}=64)$ and $1999(\mathrm{Rz}=94)$, with the peak scintillation occurrence rates being $7.5 \%$ and $15 \%$, respectively. To understand the effect of solar activity on the seasonal dependence of the scintillation activity, the data are grouped according to the three seasons, and the variation in the scintillation occurrence rate with mean sunspot number (Rz) for the three groups is shown in Fig. 5. It is noted that the scintillation occurrence rate linearly increases with Rz during winter and equinox months (Rastogi et al., 1990; Pathan et al., 1991), where as during the summer months no discernible patterns are seen.

\subsection{Effect of magnetic activity}

The effect of magnetic activity was examined by comparing scintillation occurrence rates on five (international) quiet $(\mathrm{Q})$ and five disturbed (D) days in each month. Percentage occurrence rates of the scintillations on Q- and D-days, derived from our data, are shown in Figs. 6a-d. On disturbed days in winter and near equinoxes scintillations are seen to be inhibited during the pre-midnight period and increased during the post-midnight period (specially after 04:00 LT). In the summer season scintillations on disturbed days are more pronounced before midnight and are suppressed after midnight. On an annual basis a clear suppression of scintillations on
VARANASI, 1991-1999.
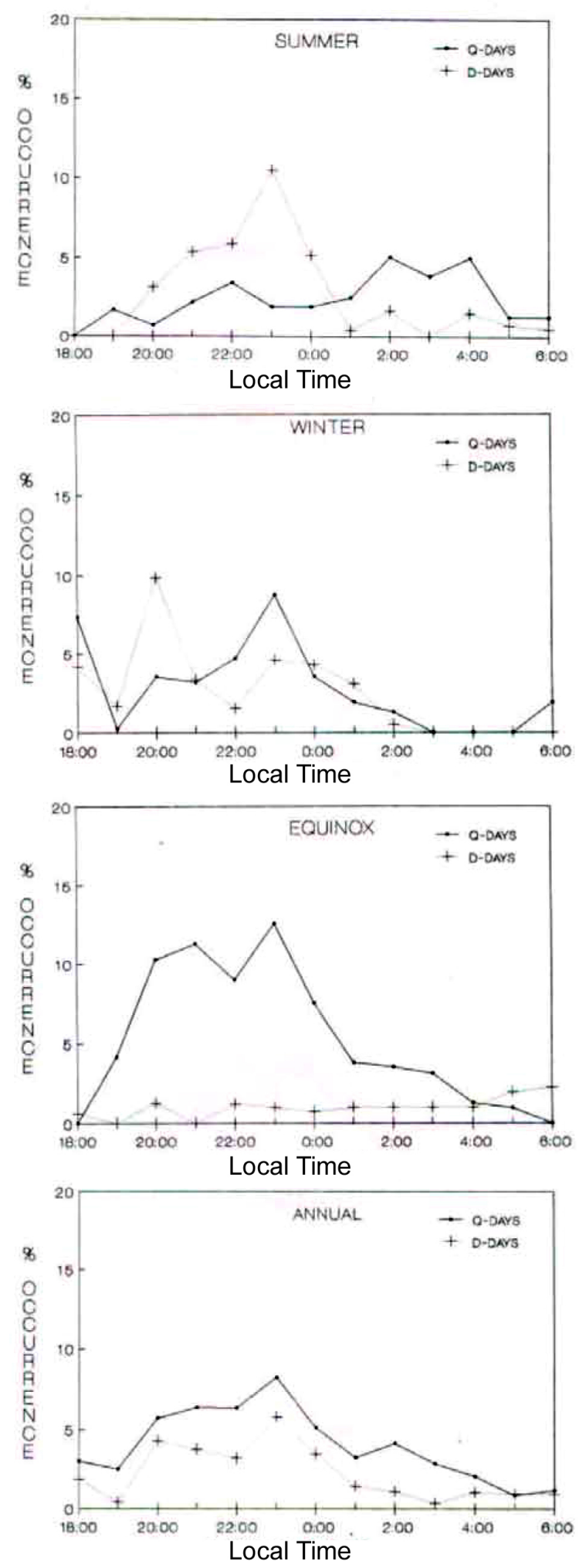

Fig. 6. Variation of the occurrence of scintillation over Varanasi on magnetically quiet and disturbed days in different seasons are given as summer, winter, equinox and annual. 
the D-days both during pre-midnight and post-midnight periods is seen. This suppression is more significant during the high solar activity years (Singh et al., 1993; Singh and Singh, 1997). The inhibition and enhancement of the irregularities during geomagnetic disturbances can be attributed to changes in ring current (Aarons, 1991). During the presunset period, the eastward electric field is increased, causing an increase in F-layer height (Fejer et al., 1999). A negative excursion of ring current during this period would lower the local eastward electric field and reduce the F-layer height. This effect may sometimes be large enough to reverse the upward movement of F-layer during the post-sunset period, thereby inhibiting the creation of irregularities. This may result in a suppression of pre-midnight scintillations over most longitudes during periods of intense magnetic activity. However, scintillations may continue to appear at some longitudes. At midnight and during the post-midnight period when the electric field is westward and the F-layer height is falling, the ring current may create a short-lived eastward electric field. This may cause the F-layer height to rise momentarily before falling again. Such a situation may create irregularities and this might be the cause of scintillations during midnight and post-midnight periods. Sastri et al. (2000) have suggested that, even in the presence of favorable conditions, like an eastward electric field, some as yet unidentifiable factors may suppress the generation of fresh irregularities in the post-midnight period. Using the measurements of thermospheric neutral wind and irregularities drift, Valladares et al. (2002) have investigated the coupling between ions and neutrals at the equatorial latitudes. They have related the variability of this coupling to the occurrence of scintillations.

\subsection{Effect of magnetic storms}

Different phases of geomagnetic storms affect the generation and development of ionospheric irregularities differently. The $D_{s t}$ index, which is a measure of the ring current and is obtained from $\mathrm{B}_{H}$ data, is used to understand the effect on scintillations. The available theories which model the effect of ring currents on the generation of equatorial Fregion irregularities depend on the timing of the maximum negative $D_{s t}$ excursion vis-a-vis local time (DasGupta et al., 1985; Aarons, 1991; Basu et al., 2001a, b). Studies on the generation of range type spread-F and VHF scintillations during the post-midnight period when geomagnetic storms are active have been reported (Aarons, 1991; Pathak et al., 1995). In this section the association of magnetic storms with the occurrence of scintillations at Varanasi is examined. Aarons (1991) has hypothesized three basic effects of the ring current in the generation or inhibition of F-layer irregularities during magnetic storms. These are:

\section{- Category-I}

If the large excursion of $D_{s t}$ occurs in the midnight and post-midnight period, the F-layer rises and then falls and irregularities are generated.

\section{- Category-II}

If the maximum excursion of $D_{s t}$ takes place during daytime hours well before sunset, the normal uplift of the F-layer is disturbed and occurrence of irregularities during that night are inhibited.

\section{- Category-III}

If the large excursion of $D_{s t}$ takes place after sunset but before midnight, the F-layer uplift is disturbed and irregularities are generated on the undisturbed nights when $D_{s t}$ has recovered to the normal value.

In the present work storms for which $D_{s t}$ goes below $-50 \mathrm{nT}$ have been selected for study. A total of 50 storms were seen during the observation period for which scintillations were recorded. Out of these 50 events scintillations were observed only in the case of 22 events (Table 1). In the remaining 28 storms no scintillations were observed. Night 0 indicates the night of onset of the storm, and nights 1 and 2 are the next two nights. From the table, it may be concluded that for the storms for which the recovery phase starts after midnight and the $D_{s t}$ is below $-100 \mathrm{nT}$, the probability of occurrence of scintillations during this period is enhanced. This is in accordance with results reported earlier by Das Gupta et al. (1985). No such relation was observed with pre-midnight excursions of $D_{s t}$ at low latitudes (Das Gupta et al., 1985).

\subsubsection{Examples of Category-I}

Figures 7-9 represent a few cases of scintillation activity during post-midnight hours along with $D_{s t}$ and $K_{p}$ variations (two middle panels). The top panel shows the ionospheric Flayer height variation at Ahmedabad and the bottom panel contains the scintillation index in $\mathrm{dB}$ (Whitney et al., 1969). Figure 7 shows a magnetic storm for the period 14-17 August 1991. From about 22:30 LT on 14 August, the $D_{s t}$ value started decreasing and attained the lowest value of $-78 \mathrm{nT}$ at 05:30 LT on 15 August, 1991. The $K_{p}$ index varied up to $5_{+}$. It is seen from the top panel that the normal height of F-layer is seriously affected. On 16-17 August 1991 intense scintillations with fast fading rates were seen during the recovery phase at 23:15-00:30 LT and at 01:30-02:45 LT. During this period the F-layer height increased rapidly to about $430 \mathrm{~km}$ and then fell to about $300 \mathrm{~km}$.

In Fig. 8 we have shown the results during a moderate magnetic storm for the period 29-31 December 1998. From about 11:30 LT, the $D_{s t}$ value started decreasing and attained the lowest value of $-54 \mathrm{nT}$ at 16:30 LT. The $D_{s t}$ value shows a minimum of $-53 \mathrm{nT}$ and $-52 \mathrm{nT}$ at 00:30 LT and 04:30 LT, respectively, on 30 December. The $K_{p}$ value shows a maximum of $5_{0}$ at 02:30 LT on 30 December in the post-midnight period. Scintillations occurred during 17:45-18:15 LT on 29 December and during 06:15-11:15 LT on 30 December. These events were intense with a fast fading rate and extending well into the recovery phase of the storm. During this pe$\operatorname{riod}(06: 15-11: 15 \mathrm{LT})$ the F-layer height increased rapidly to 
Table 1. Nighttime scintillation activity for the geomagnetic storm $\left(D_{s t}<-50 \mathrm{nT}\right)$, IST=UT $+5.5 \mathrm{~h}$; O=Scintillation present; $-=\mathrm{No}$ Scintillation; $\mathrm{ND}=$ No Data.

\begin{tabular}{|c|c|c|c|c|c|c|c|c|c|c|c|c|}
\hline \multirow{2}{*}{$\begin{array}{r}S \\
\text { No. }\end{array}$} & \multirow[t]{2}{*}{ Storm day } & \multirow{2}{*}{$\begin{array}{l}\text { Main } \\
\text { phase on } \\
\text { set time } \\
\text { (hours) }\end{array}$} & \multirow{2}{*}{$\begin{array}{l}\text { Magnitude } \\
\text { of storm } \\
\text { (nT) }\end{array}$} & \multirow{2}{*}{$\begin{array}{c}\text { Main } \\
\text { phase } \\
\text { duration } \\
\text { (hours) }\end{array}$} & \multirow{2}{*}{$\begin{array}{l}\text { Recovery } \\
\text { phase } \\
\text { duration } \\
\text { (hours) }\end{array}$} & \multirow{2}{*}{$\begin{array}{l}\text { Longevity } \\
\text { of storm } \\
\text { (hours) }\end{array}$} & \multicolumn{2}{|c|}{ Night 0} & \multicolumn{2}{|c|}{ Night 1} & \multicolumn{2}{|c|}{ Night 2} \\
\hline & & & & & & & Pre & Post & Pre & Post & Pre & Post \\
\hline 1. & 24 March 1991 & 06 & -298 & 19 & 121 & 143 & $\mathrm{O}$ & $\mathrm{O}$ & - & $\mathrm{O}$ & - & - \\
\hline 2. & 17 May 1991 & 02 & -103 & 08 & 56 & 69 & - & - & - & $\mathrm{O}$ & ND & ND \\
\hline 3. & 10 June 1991 & 07 & -131 & 07 & 10 & 17 & $\mathrm{O}$ & - & ND & $\mathrm{ND}$ & $\mathrm{O}$ & $\mathrm{O}$ \\
\hline 4. & 8 July 1991 & 20 & -198 & 19 & 69 & 90 & - & - & $\mathrm{O}$ & $\mathrm{O}$ & ND & ND \\
\hline 5. & 13 July 1991 & 21 & -185 & 19 & 71 & 91 & $\mathrm{O}$ & - & - & - & - & - \\
\hline 6. & 14 August 1991 & 17 & -78 & 07 & 42 & 50 & - & - & - & - & $\mathrm{O}$ & $\mathrm{O}$ \\
\hline 7. & 19 August 1991 & 01 & -170 & 08 & 132 & 142 & $\mathrm{O}$ & - & $\mathrm{O}$ & - & - & - \\
\hline 8. & 28 October 1991 & 12 & -251 & 20 & 208 & 228 & $\mathrm{O}$ & $\mathrm{O}$ & $\mathrm{O}$ & - & ND & ND \\
\hline 9. & 9 May 1992 & 24 & -297 & 15 & 118 & 136 & - & - & - & - & - & $\mathrm{O}$ \\
\hline 10. & 22 May 1992 & 06 & -111 & 11 & 62 & 73 & $\mathrm{ND}$ & $\mathrm{ND}$ & ND & $\mathrm{O}$ & - & ND \\
\hline 11. & 5 August 1992 & 01 & -81 & 08 & 64 & 74 & - & $\mathrm{O}$ & - & - & - & - \\
\hline 12. & 22 August 1992 & 11 & -113 & 16 & 69 & 87 & $\mathrm{O}$ & - & ND & $\mathrm{ND}$ & $\mathrm{O}$ & - \\
\hline 13. & 28 December 1992 & 09 & -108 & 22 & 49 & 106 & - & - & - & - & $\mathrm{O}$ & - \\
\hline 14. & 11 March 1993 & 10 & -120 & 09 & 61 & 70 & ND & $\mathrm{ND}$ & ND & $\mathrm{ND}$ & $\mathrm{O}$ & - \\
\hline 15. & 3 November 1993 & 24 & -116 & 12 & 124 & 152 & ND & $\mathrm{ND}$ & - & - & - & - \\
\hline 16. & 18 November 1993 & 12 & -78 & 08 & 46 & 55 & $\mathrm{O}$ & $\mathrm{O}$ & - & - & - & $\mathrm{O}$ \\
\hline 17. & 1 December 1993 & 13 & -111 & 12 & 54 & 77 & ND & $\mathrm{ND}$ & - & - & - & - \\
\hline 18. & 26 August 1998 & 10 & -188 & 24 & 204 & 228 & ND & $\mathrm{ND}$ & - & - & - & - \\
\hline 19. & 5 November 1998 & 12 & -148 & 19 & 79 & 98 & ND & $\mathrm{ND}$ & - & - & - & - \\
\hline 20. & 29 December 1998 & 06 & -52 & 13 & 32 & 46 & $\mathrm{O}$ & $\mathrm{O}$ & - & $\mathrm{O}$ & - & - \\
\hline 21. & 18 February 1999 & 04 & -132 & 11 & 81 & 92 & - & - & - & - & - & - \\
\hline 22. & 16 April 1999 & 11 & -105 & 18 & 99 & 117 & - & - & - & - & - & - \\
\hline
\end{tabular}

about $380 \mathrm{kms}$ and then decreased to about $250 \mathrm{kms}$. On 31 December scintillations were also recorded between 07:0012:05 LT. This observation was just preceded by a disturbed F-layer. The $K_{p}$ index was $2_{-}$. Thus, we can associate the rise and fall of the F-layer with F-region irregularities.

Figure 9 shows a magnetic storm with slow recovery during 18-20 November 1993. $D_{s t}$ value decreases sharply and attains the minimum value of $-78 \mathrm{nT}$ at $01: 30 \mathrm{LT}$ on 19 November 1993. The $K_{p}$ value varies between $1_{-}$and $6_{+}$during the storm period. The F-layer rises during the post-midnight period (05:00 LT) on 19 November up to $350 \mathrm{kms}$ and then decreases to $200 \mathrm{kms}$ (minimum height). On 20 November again, F-layer goes up to $400 \mathrm{kms}$ at 05:00 LT. Scintillations are observed on 19 November, during 22:30-01:15 LT and on 20 November, between 04:0004:45 LT. It may be noted that the first event of scintillation started in the main phase of the storm, whereas the second event was in the recovery phase. The first event of scintillation (Figs. 8 and 9) associated with a sharp decrease in $D_{s t}$ may be caused by a prompt penetration of the electric field into the equatorial ionosphere with a consequent sudden onset of irregularities (Basu et al., 2001a).
The above discussion shows that magnetic storms for which the recovery phase starts in the post-midnight to dawn period and for which $D_{s t}$ goes below $-50 \mathrm{nT}$, are usually associated with intense scintillations during the post-midnight period. $D_{s t}$ acquiring a maximum negative value suggests that the ring current has a peak value at that time. Thus, the ring current may be a controlling factor in the development of F-region irregularities (DasGupta et al., 1985; Aarons, 1991). Generation of irregularities in the post-midnight during enhanced geomagnetic activity has been reported from Jicamarca radar measurements (Fejer et al., 1999).

\subsubsection{Examples of Category-II}

Figures 10 and 11 show the scintillation activity during the magnetic storm of 28-31 October 1991 and 4-8 August 1992 , respectively when the $D_{s t}$ minimum occured during the daytime. From Fig. 10 we find that $D_{s t}$ started decreasing at about 16:24 LT, passed through a local minimum at 21:30 LT on 28 October and attained the lowest value of $-251 \mathrm{nT}$ at 13:30 LT on 29 October, with an $A_{p}$ index of 128 and a $K_{p}$ index varying between $5_{-}$and $8_{-}$. The F-layer 

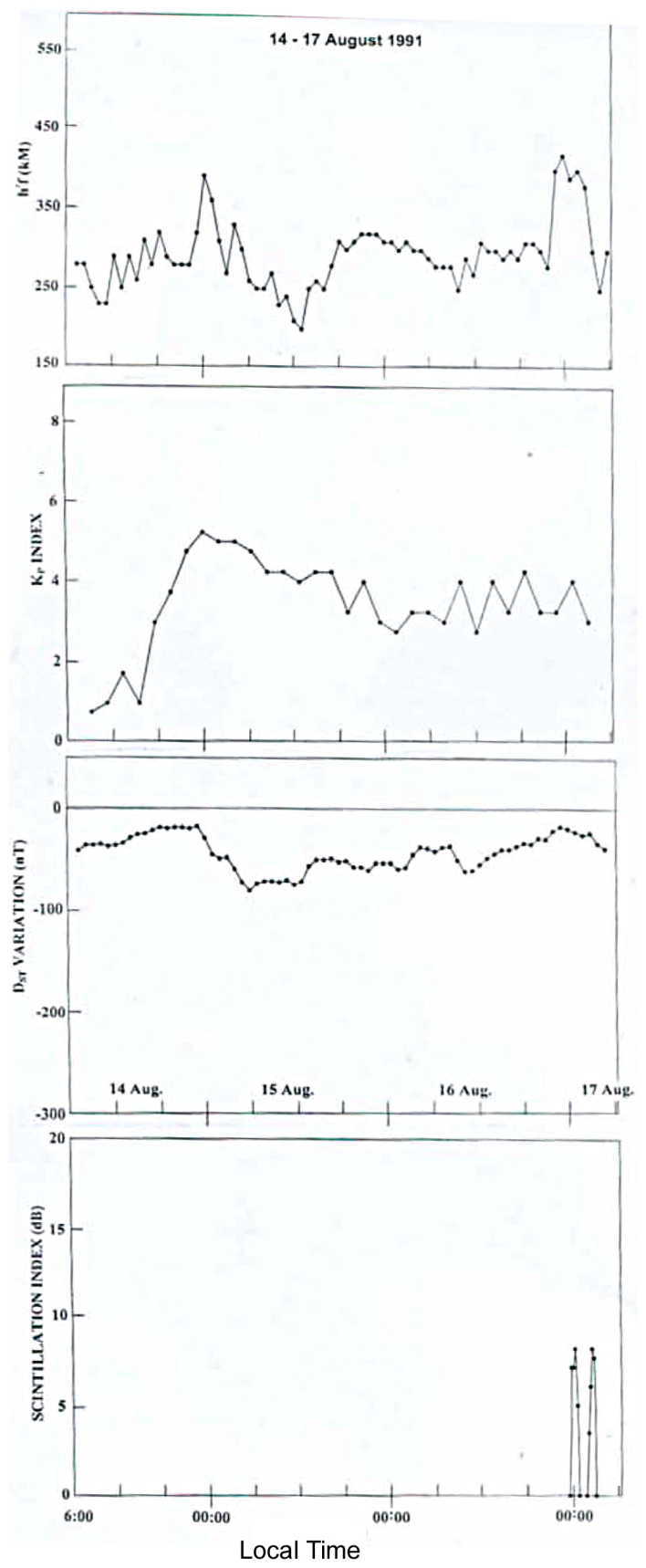

Fig. 7. Example of a magnetic storm that occurred during 14-17 August 1991. The top panel is ionospheric F-layer height $\left(\mathrm{h}^{\prime} \mathrm{F}\right)$ at Ahmedabad, the two middle panels are $K_{p}$ and $D_{s t}$ and the bottom panel shows the occurrence times of scintillation activity at Varanasi.

height fluctuated rapidly during the magnetic storm. Scintillations are observed on 28 October during 21:45-23:15 LT just when the $D_{s t}$ is through a local minimum. Scintillations of 29 October occurred during 05:00-07:00 LT while $D_{s t}$ activity was decreasing before the main storm. A weak scintillation event is also seen during 22:45-23:15 LT on 29 October. Although fluctuation in the F-layer height was observed post-midnight on both 29 and 30 October, but no scintilla-
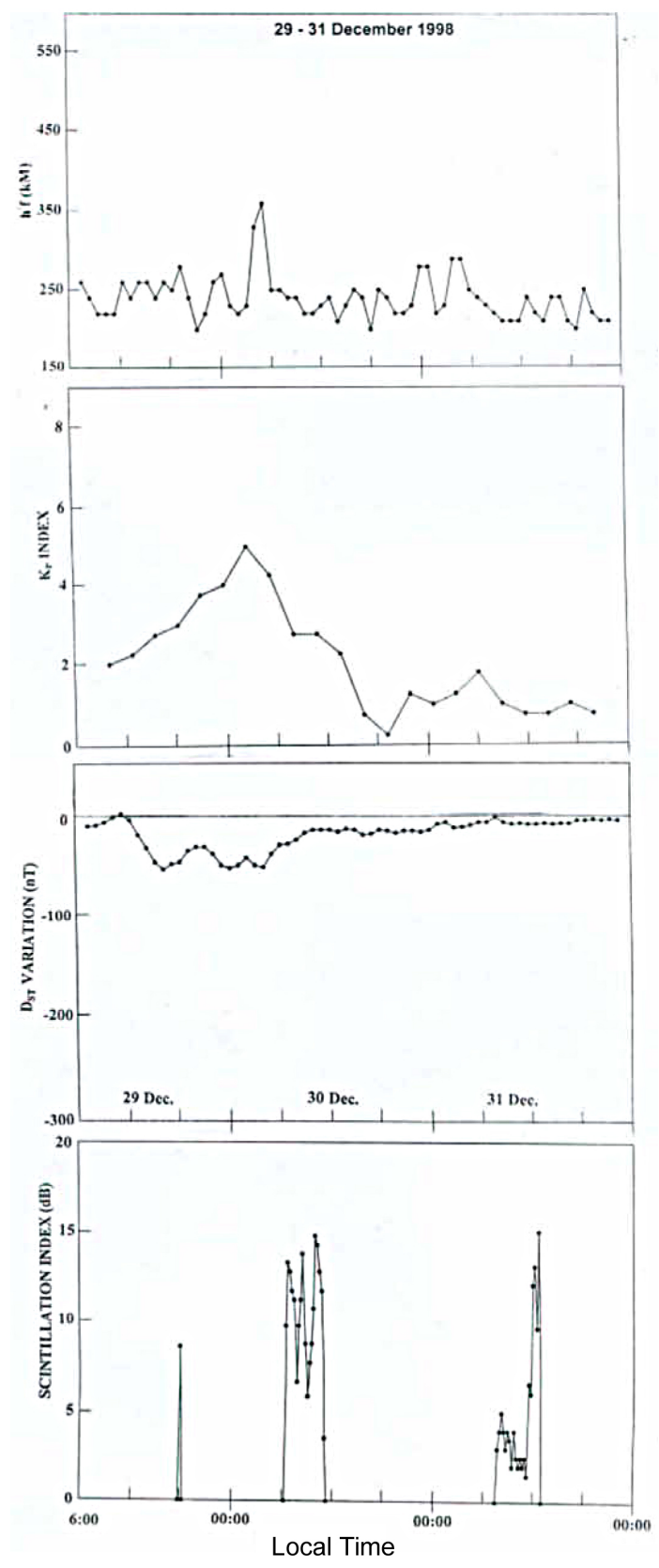

Fig. 8. Example of a magnetic storm that occurred during 29-31 December 1998. The top panel is ionospheric F-layer height $\left(h^{\prime} \mathrm{F}\right)$ at Ahmedabad, the two middle panels are $K_{p}$ and $D_{s t}$ and the bottom panel shows the occurrence times of scintillation activity at Varanasi.

tion was observed. These observations are consistent with generation of scintillations in the main phase of the storm and a suppression of scintillations in the recovery phase. The scintillations in the pre-midnight period on 28 October are attributed to a prompt penetration of the magnetospheric electric field (Basu et al., 2001a, b), while the post-midnight scintillations are freshly generated irregularities caused by the disturbance dynamo electric field (Basu et al., 2001a; Bhattacharya et al., 2002). 


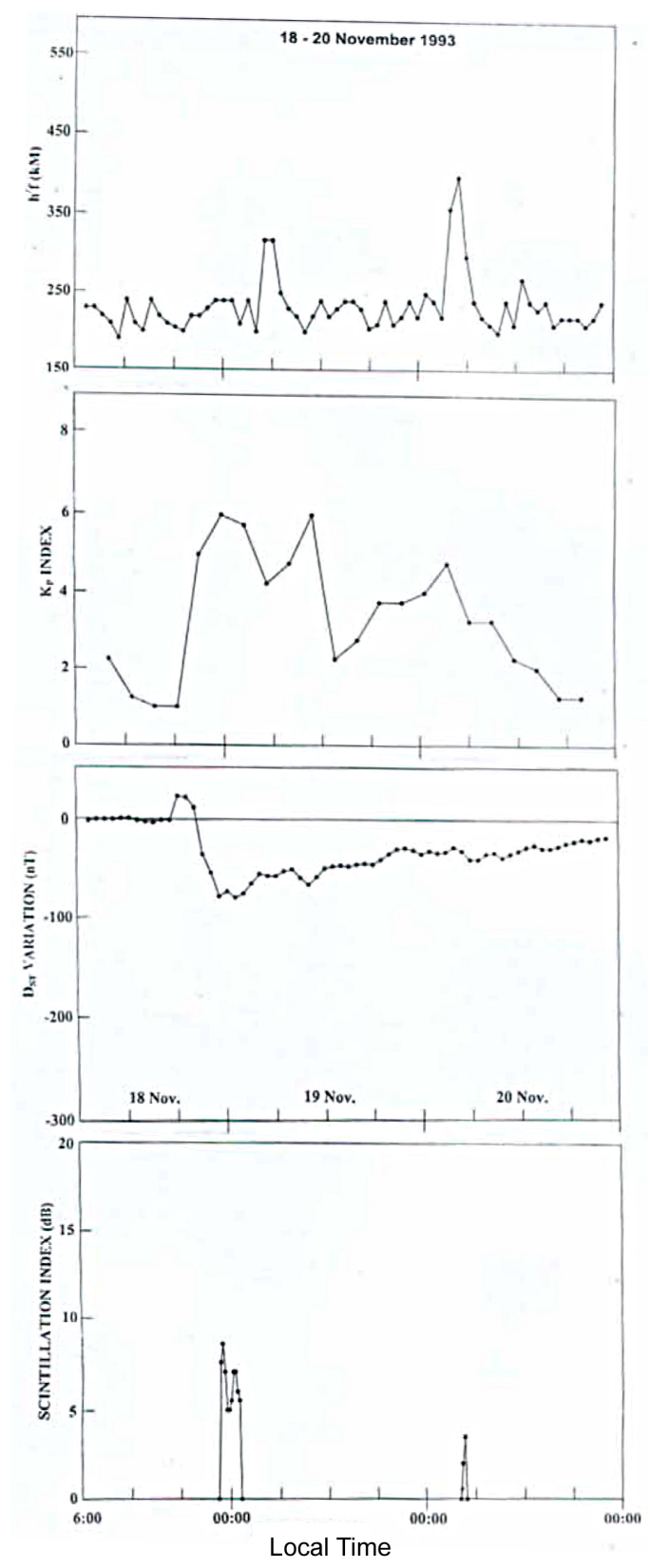

Fig. 9. Example of a magnetic storm that occurred during 18-20 November 1993. The top panel is ionospheric F-layer height $\left(\mathrm{h}^{\prime} \mathrm{F}\right)$ at Ahmedabad, the two middle panels are $K_{p}$ and $D_{s t}$ and the bottom panel shows the occurrence times of scintillation activity at Varanasi.

The magnetic storm of 5-9 August 1992 occurred at 14:30 LT on 5 August, with a minimum $D_{s t}$ value of $-80 \mathrm{nT}$ and its $K_{p}$ index varied between $2_{+}$to $6_{-}$(Fig. 11). The F-layer height showed an oscillation between 200 and $380 \mathrm{kms}$. Scintillations were observed only on 8 August during 21:15-03:30 LT, just after the recovery phase of the storm. This indicated that scintillations are not created during and after the recovery phase, if the recovery phase was in the daytime, even if the $D_{s t}$ went below $-75 \mathrm{nT}$.

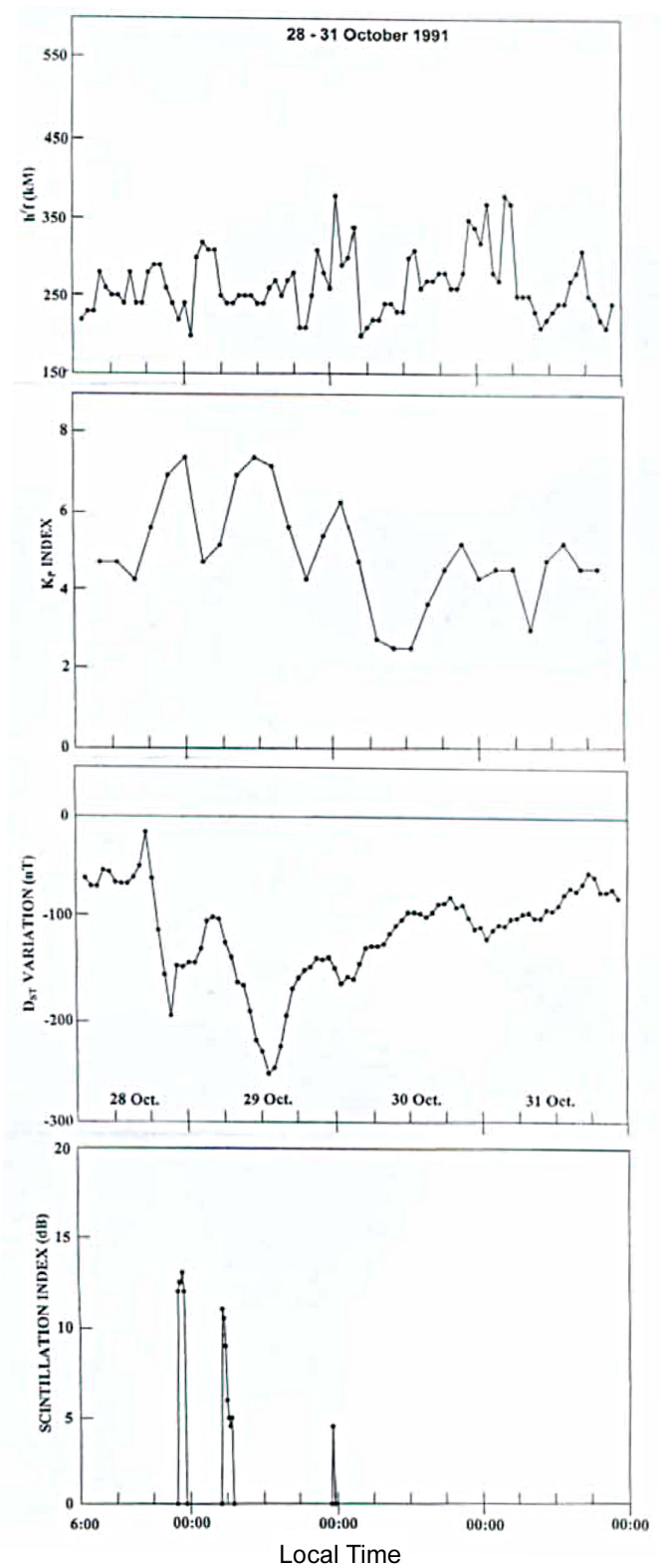

Fig. 10. Example of a magnetic storm that occurred during 28-31 October 1991. The top panel is ionospheric F-layer height $\left(h^{\prime} \mathrm{F}\right)$ at Ahmedabad, the two middle panels are $K_{p}$ and $D_{s t}$ and the bottom panel shows the occurrence times of scintillation activity at Varanasi.

\subsubsection{Examples of Category-III}

Examples of scintillation activities under severe magnetic storms following the $D_{s t}$ minimum, occurring in the premidnight periods are presented in Figs. 12 and 13. The magnetic storm of 12-15 July 1991 commenced at 15:00 LT on $12 \mathrm{July}$, and the $D_{s t}$ value attained the minimum value of $-185 \mathrm{nT}$ at 21:30 LT on 13 July (Fig. 12). The $A_{p}$ index was 134 , with $K_{p}$ varying between $5_{-}$and $99_{-}$. At the time 

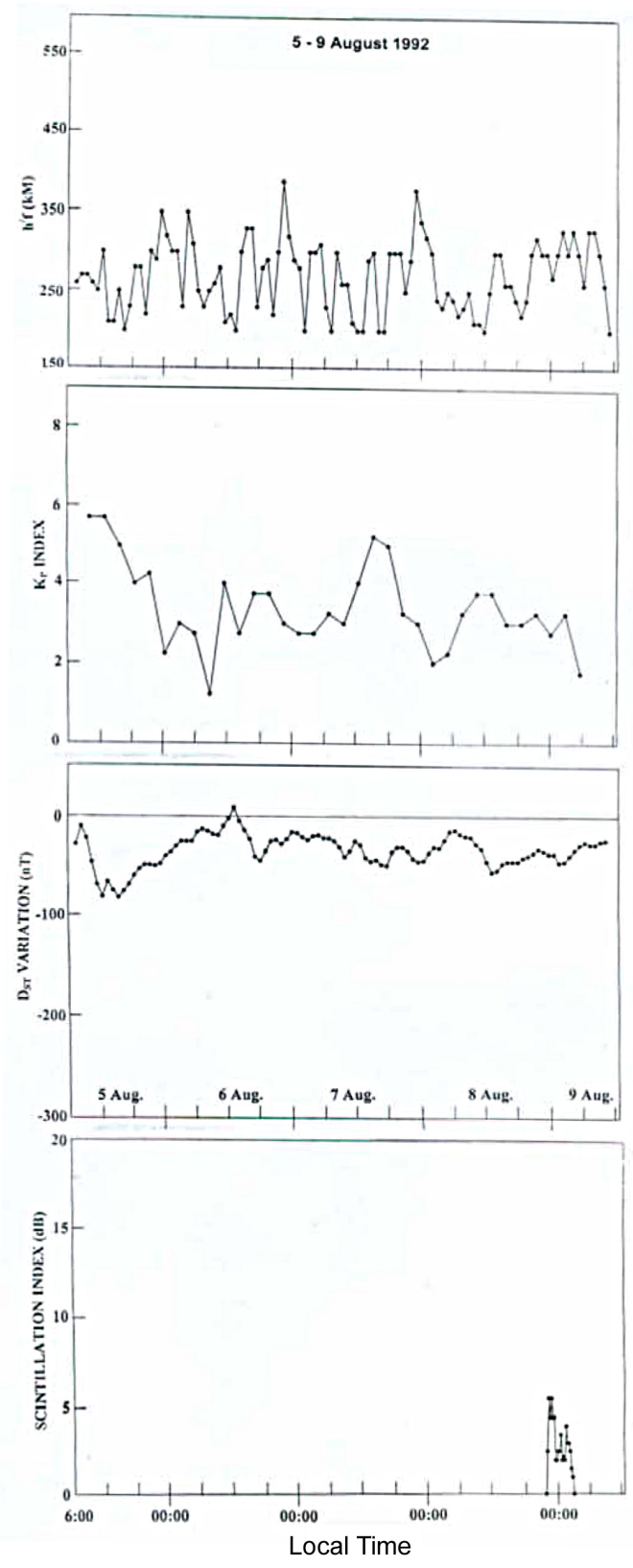

Fig. 11. Example of a magnetic storm that occurred during 05-09 August 1992. The top panel is ionospheric F-layer height $\left(h^{\prime} F\right)$ at Ahmedabad, the two middle panels are $K_{p}$ and $D_{s t}$ and the bottom panel shows the occurrence times of scintillation activity at Varanasi.

of the maximum $D_{s t}$ excursion the F-layer quickly ascended to $573 \mathrm{~km}$. This is associated with the onset of spread-F in the post-sunset period. The F-layer in the post-sunset period on 12,14 and 15 July reached $420 \mathrm{~km}, 450 \mathrm{~km}$ and $400 \mathrm{~km}$, respectively. Weak scintillations $(\sim 2 \mathrm{~dB})$ are observed during 22:45-23:45 LT on 13 July and between 01:00 and 02:00 LT on 14 July. We notice that even though the rise and fall of the F-layer is very large, only weak scintillations are generated on the night of 13-14 July. This is in agreement

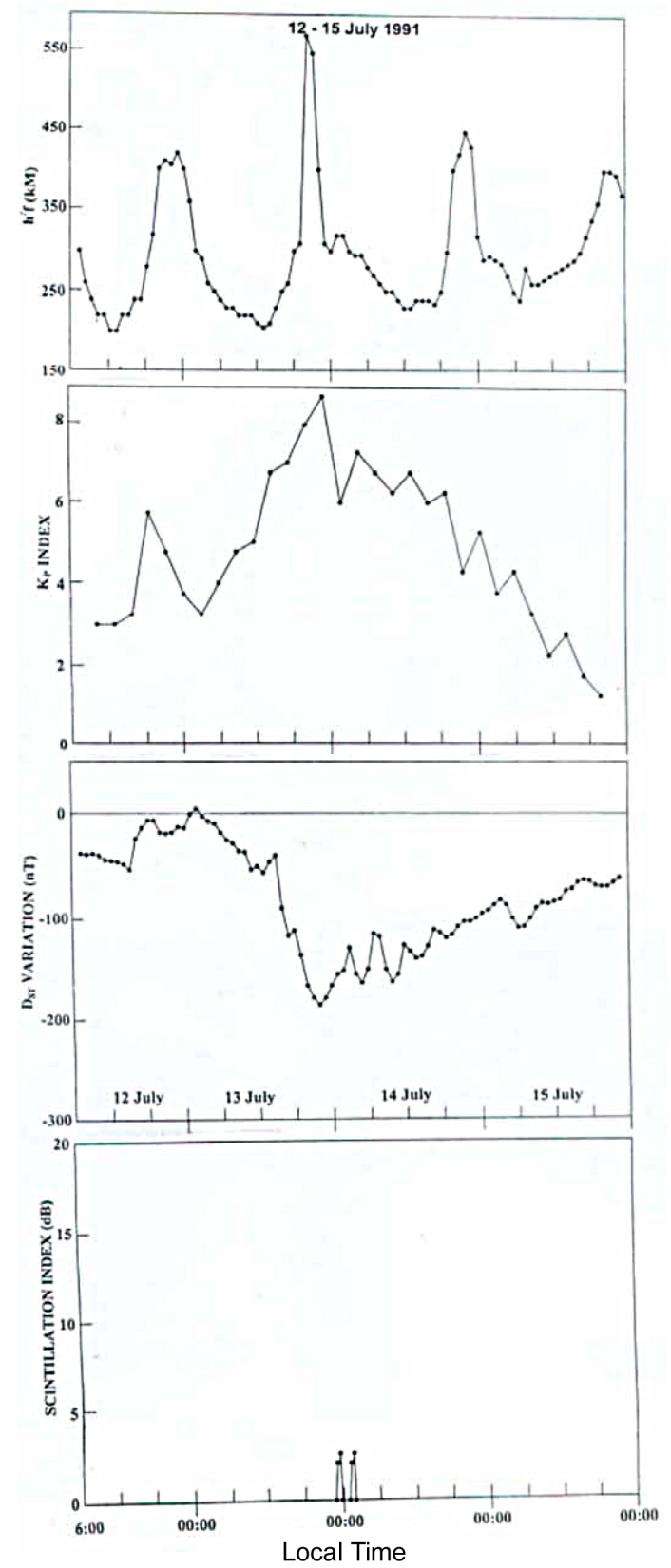

Fig. 12. Example of a magnetic storm that occurred during 12-15 July 1991. The top panel is ionospheric F-layer height $\left(h^{\prime} \mathrm{F}\right)$ at Ahmedabad, the two middle panels are $K_{p}$ and $D_{s t}$ and the bottom panel shows the occurrence times of scintillation activity at Varanasi.

with the observations of Banola et al. (2001) for the same magnetic storm at the equatorial station Trivandrum. During $D_{s t}$ excursions in the pre-midnight period, the eastward electric field is enhanced and consequently, the F-layer along with the irregularities formed at the bottom of the F-layer are lifted upwards (Fejer, 1981; Banola et al., 2001).

In the magnetic storm of 10-14 May 1992 (Fig. 13) the minimum $D_{s t}$ value reached a low value of $-300 \mathrm{nT}$ at 

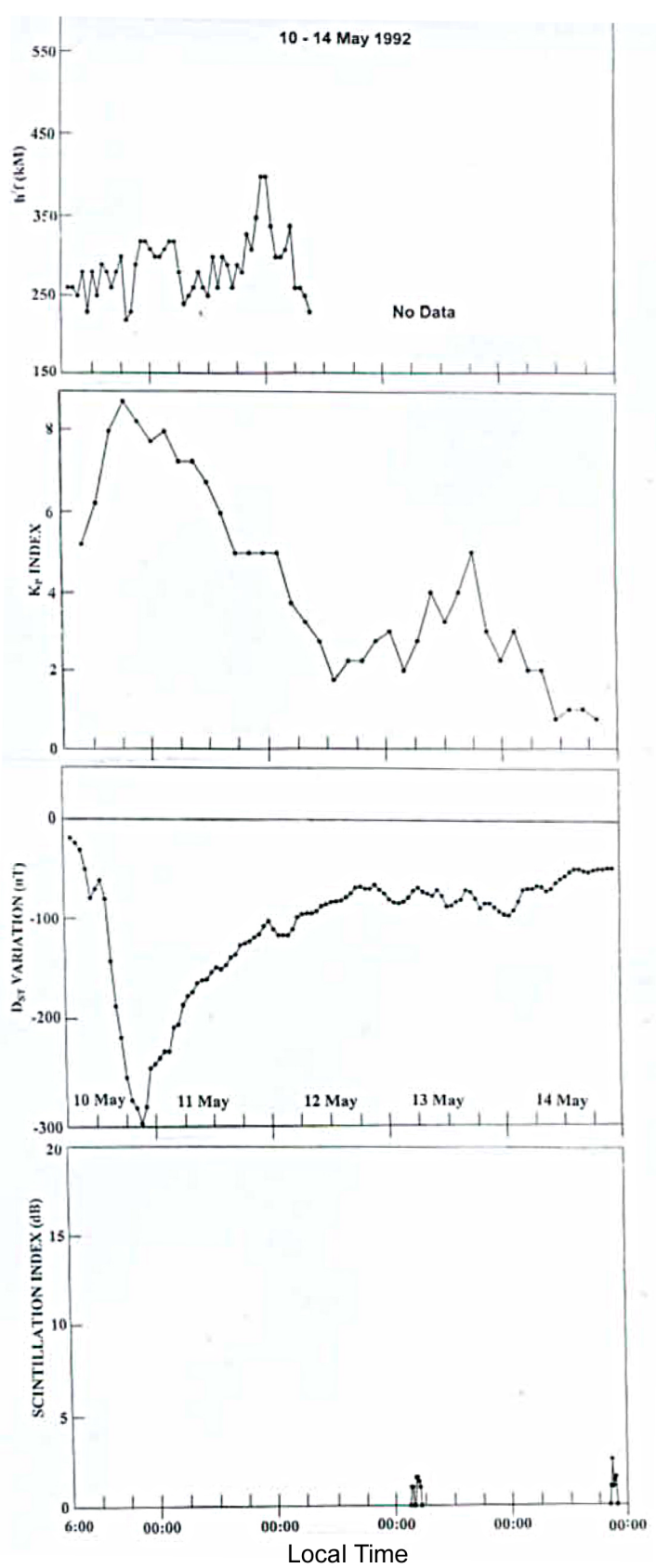

Fig. 13. Example of a magnetic storm that occurred during 10-14 May 1992. The top panel is ionospheric F-layer height $\left(\mathrm{h}^{\prime} \mathrm{F}\right)$ at Ahmedabad, the two middle panels are $K_{p}$ and $D_{s t}$ and the bottom panel shows the occurrence times of scintillation activity at Varanasi.

20:30 LT on 10 May 1992, with $K_{p}$ varying between $6_{+}$to 9_. Scintillations are observed on 13 May at 03:00-05:00 LT and on 14 May, at 20:30-22:00 LT, but the intensity is weak $(<3 \mathrm{~dB})$. This shows that when the maximum $D_{s t}$ excursion occurs in the pre-midnight period, no scintillations are generated during the next two days and weak scintillation may be observed on the third day during the post-midnight period. Unfortunately, no data for the F-layer height is available during the period of the scintillations.
During magnetospheric disturbances, coupling of the high latitude and the magnetospheric current systems with the equatorial electric fields possibly causes a direction reversal of the electric fields from westward to eastward (Gonzales et al., 1979). This plays a significant role in the generation and growth of F-region irregularities and explains the magnetic storm-induced post-midnight scintillations extending into the daytime (Chandra et al., 1995; Chakraborty et al., 1999; Basu et al., 2001a; Bhattacharya et al., 2002). The equatorial dynamo electric field is also disturbed during a magnetic storm and this also affects the irregularities (Basu et al., 2001a; Bhattacharya et al., 2002). The behaviour of the equatorial electric fields during a storm has been studied and attempts have been made to delineate the relative contributions of prompt penetration and disturbance dynamo electric fields (Fejer and Scherliess, 1997; Scherliess and Fejer, 1997).

\section{Summary}

The irregularities at low latitudes are observed at irregular intervals and their duration increases as one moves closer to the geomagnetic equator. The irregularities observed during summer months are relatively weak as compared to those recorded during winter and equinox months. The enhancement in magnetic activity leads to a suppression of pre-midnight scintillations during the equinoxes and during the winter, whereas an enhancement is observed in summer months.

The generation or inhibition of irregularities during the main phase/recovery phase of a magnetic storm depends upon the location of the station and local time. If a storm occurs post-midnight, then scintillations are observed during main and recovery phase. On the other hand, when a storm occurs during the daytime no scintillation is observed during the night of the recovery phase. Weak scintillations observed during the recovery phase in some magnetic storms is attributed to freshly generated irregularities caused by disturbance dynamo electric fields (Basu et al., 2001a, b). In the third case when a storm occurs after sunset and before midnight, the F-layer is disturbed but scintillations are observed only during the undisturbed night when $D_{s t}$ has recovered to the normal value (Fig. 13). In some cases (Fig. 12) we have observed very weak scintillations $(\sim 2 \mathrm{~dB})$ in the beginning of recovery phase of the storm.

The inhibition and generation of irregularities during enhanced magnetic activity period are explained by considering changes in the electric field. The role of the storm time electric field is very complex. It appears that the magnetospheric electric field changes related to the ring current intensification are not sufficient to explain all of the observations of inhibition and the generation of low-latitude ionospheric irregularities during the night. Apart from the ring current, there are several other factors which shape the development of irregularities, such as the ion-neutral collision frequency, neutral wind, large scale plasma density gradient, gravity wave, 
etc. A magnetic storm enhances the interplay of these parameters and hence their contributions should be considered separately.

Acknowledgements. The work is financially supported by the Department of Science and Technology, New Delhi under SERC project. A. K. Singh thanks the Department of Science and Technology, New Delhi for financial support through BOYSCAST fellowship.

Topical Editor M. Lester thanks R. E. Shechan for his help in evaluating this paper.

\section{References}

Aarons, J., Mullen, J. P., Koster, J. R., daSilva, R. F., Madeiros, J. R., Medeiros, R. T., Bushby, A., Pantoja, J., Lanat, J., and Paulson, M. R.: Seasonal and geomagnetic control of equatorial scintillations in two longitudinal sectors, J. Atmos. Terr. Phys., 42, 861-866, 1980.

Aarons, J. and DasGupta, A.: Equatorial scintillations during the major magnetic storm of April 1981, Radio Sci., 19, 731-739, 1984.

Aarons, J.: Equatorial F-layer irregularity patches at anomaly latitudes, J. Atmos. Terr. Phys., 47, 875-883, 1985.

Aarons, J.: The role of the ring current in the generation and inhibition of equatorial F-layer irregularities during magnetic storms, Radio Sci., 26, 1131-1149, 1991.

Aarons, J. and Basu, S.: Ionospheric amplitude and phase fluctuations at the GPS frequencies, In Proceeding of ION GPS-94, Inst. of Navig., Arlington, Va., 1569-1578, 1994.

Banola, S., Pathan, B. M., and Rao, D. R. K.: Strength of the equatorial electrojet and geomagnetic activity control on VHF scintillations at the Indian longitudinal zone, Ind. J. of Radio and Space Phys., 30, 163-171, 2001.

Basu, S. and Basu, Su.: Scintillation technique for probing ionospheric irregularities, in World Ionospheric/Thermospheric Studies (WITS) Handbook, vol 2, edited by Liu, C. H., SCOSTEP, University of Ill., Urbana, 128-130, 1989.

Basu, S., Bishop, G. J., and Larson, J.: Turbulence in the upper atmosphere: Effects on systems, AGARD Conf. Proc., AGARDCP-573, 24A-1-24A-9, 1995.

Basu, S., Basu, Su., Groves, K. M., Yeh, H. C., Su, S. Y., Rich, F. J., and Sultan, P. J.: Response of the equatorial ionosphere in the South Atlantic region to the great magnetic storm of $15 \mathrm{July}$, 2000, Geophys. Res. Lett., 28, 3577-3580, 2001a.

Basu, Su., Basu, S., Valladares, C. E., Yeh, H. C., Su, S. Y., MacKenzie, E., Sultan, P. J., Aarons, J., Rich, F. J., Doherty, P., Groves, K. M., and Bullett, T. W.: Ionospheric effects of major magnetic storms during the international space weather period of September and October 1999: GPS observations, VHF/UHF scintillations and in situ density structures at middle and equatorial latitudes, J. Geophys. Res., 106, 30 389-30 413, 2001 b.

Bhattacharya, A., Basu, S., Groves, K. M., Valladares, C. E., and Sheehan, R.: Effect of magnetic activity on the dynamics of equatorial F region irregularities, J. Geophys. Res., 107 (A12), 1489, 2002.

Chakraborty, S. K., DasGupta, A., Ray, S., and Banerjee, S.: Long term observations of VHF scintillation and total electron content near the crest of the equatorial anomaly in the Indian longitude zone, Radio Science,34, 241-255, 1999.
Chandra, H., Vyas, G. D., Rao, D. R. K., Pathan, B. M., Iype, A., Sekaran, B. R., Naidu, A., Sadique, S. M., Salgaonkar, C. S., Tyagi, T. R., Vijay Kumar, P. N., Lakha Singh, Iyer, K. N., Pathak, K. N., Gwal, A. K., Kumar, S., Singh, R. P. Singh, U. P., Singh, B., Jain, V. K., Navneeth, G. N., Koparkar, P. V., Rama Rao, P. V. S., Jaychandram, P. T., Sriram, P., Santa Rao, N. Y. S., Das Gupta, A. Basu, K., and Rastogi, R. G.: Coordinated multistation VHF scintillation observations in India during MarchApril 1991, Ind. J. Radio \& Space Physics, 22, 69-81, 1993.

Chandra, H., Vyas, G. D., Pathan, B. M., and Rao, D. R. K.: Spectral characteristics of magnetic storm induced F-region scintillations extending in to daytime, J. Atmos. Terr. Phys., 57, 1273 1285, 1995.

Chandra, H. and Rastogi, R. G.: Scintillations of satellite signals near magnetic equator, Current Sci., 43, 567-568, 1974.

Dabas, R. S., Lakshmi, D. R., and Reddy, B. M.: Effect of geomagnetic disturbances on the VHF nighttime scintillation activity at equatorial and low latitudes, Radio Sci., 24, 563-573, 1989.

DasGupta, A., Maitra, A., and Basu, S.: Occurrence of nighttime VHF scintillation near the equatorial anomaly crest in the Indian Sector, Radio Sci., 16, 1455-1458, 1981.

DasGupta, A., Maitra, A., and Das, S. K.: Post-midnight scintillation activity in relation to geomagnetic disturbances, J. Atmos. Terr. Phys., 47, 911-916, 1985.

Fejer, B. G., Scherliess, L., and dePaula, E. R.: Effects of the vertical plasma drift velocity on the generation and evolution of equatorial spread F, J. Geophys. Res.,104, 19 859-19869, 1999.

Fejer, B. G. and Scherliess, L.: Empirical models of storm time equatorial zonal electric fields, J. Geophys. Res., 102, $24047-$ 24 056, 1997.

Fejer, B. G.: The equatorial ionospheric electric fields; A review, J. Atmos. Terr. Phys., 43, 377-386, 1981.

Fejer, B. G.: Low latitude electrodynamic plasma drifts: A review, J. Atmos. Terr. Phys., 53, 677-693, 1991.

Fejer, B. G.: The electrodynamics of the low latitude ionosphere: Recent results and future challenges, J. Atmos. Solar Terr. Phys., 59, 1465-1482, 1997.

Gonzales, C. A., Kelly, M. C., Fejer, B. G., Vickrey, J. F., and Woodman, R. F.: Equatorial electric fields during magnetically disturbed conditions, Part II: Implications of simultaneous auroral and equatorial measurement, J. Geophys. Res., 84, 5803, 1979.

Groves, K. M., Basu, S., Weber, E. J., Smithan, M., Kuenzler, H., Valladares, C. E., Sheehan, R., Mackenzie, E., Secan, J. A., Ning, P., McNeill, W. J., Moonan, D. W., and Kendra, M. J.: Equatorial scintillation and system support, Radio Science, 32, 2047-2064, 1997.

Haerendel, G.: Theory of equatorial spread-F, Rep. Max PlanckInstitut für Phys. and Astrophys., Garching, Germany, 1974.

Hari, S. S., Viswanathan, K. S., Subbarao, K. S. V. and Krishna Murthy, B. V.: Equatorial E and F-region zonal electric fields in the post sunset period, J. Geophys. Res., 101, 7947-7949, 1996.

Kelley, M. C.: The Earth's ionosphere, Academic, San Diego, California, 1989.

Koster, J. R.: Equatorial scintillations, Planetary and Space Sci., 20, 1999, 1972.

Kumar, S. and Gwal, A. K.: VHF ionospheric scintillations near the equatorial anomaly crest: solar and magnetic activity effects, J. Atmos. Solar Terr. Phys.,62, 157-169, 2000.

Mathew, B., Iyer, K. N., and Pathan, B. M.: Patchy occurrence of VHF scintillation at tropical latitudes, J. Atmos. Terr. Phys., 54, 963-968, 1992. 
Ossakow, S. L.: Spread-F theories: A review, J. Atmos. \& Terr. Phys., 43, 437-452, 1981.

Pathan, B. M., Rastogi, R. G., and Rao, D. R. K.: On the width and complexities of the equatorial nighttime radio wave scintillation belt in the Indian region, J. Geomag. Geoelec., 44, 129-142, 1992.

Pathan, B. M., Koparkar, P. V., Rastogi, R. G., and Rao, D. R. $\mathrm{K}$.: Dynamics of ionospheric irregularities producing VHF radio wave scintillations at low latitudes, Ann Geophys., 9, 126-132, 1991.

Pathak, K. N., Jivrajani, R. D., Joshi, H. P., and Iyer, K. N.: Characteristics of VHF scintillations in the equatorial anomaly crest region in India, Ann. Geophys., 13, 730-739, 1995.

Rastogi, R. G., Mullen, J. P., and Mackenzie, E.: Effect of geomagnetic activity on equatorial VHF scintillations and spread F, J. Geophy. Res., 86, 3661, 1981.

Rastogi, R. G., Koparkar, P. V., and Pathan, B. M.: Nighttime radio wave scintillation at equatorial station in Indian and American zones, J. Geomag. Geoelectr., 42, 1-10, 1990.

Sastri, J. H., Jyoti, N., Somayajulu, V. V., Chandra H., and Devasia, C. V.: Ionospheric storm of early November 1993 in the Indian equatorial region, J. Geophys. Res., 105, 18 443-18 455, 2000.

Scherliess, L. and Fejer, B. G.: Storm time dependence of equatorial disturbance dynamo zonal electric fields, J. Geophys. Res., 102, 24 037-24 046, 1997.
Singh, R. P., Singh, A. K., Singh, U. P., and Singh, R. N.: Scintillation study at Varanasi, Ind. J. Rad. Spa. Phys., 22, 17-21, 1993.

Singh, A. K. and Singh, R. P.: Observations and modeling of nocturnal ionospheric irregularities in low latitude region, J. Geomag. Geoelectr.,49, 1114, 1997.

Singh, A. K., Narayan, D., and Singh, R. P.: Weak scattering theory for ionospheric scintillations, II Nuovo Cimento (Italy), 20c, 541-552, 1997.

Valladares, C. E., Hanson, W. B., McClure, J. P., and Cragin, B. L.: Bottom side sinusoidal irregularities in the equatorial F-region, J. Geophys. Res., 88, 8025-8042, 1983.

Valladares, C. E., Meriwether, J. W., Sheehan, R., and Biondi, M. A.: Correlative study of neutral winds and scintillation drifts measured near the magnetic equator, J. Geophys. Res., 107(A7), 2002.

Vyas, G. D. and Chandra, H.: VHF scintillation and spread-F in the anomaly crest region, Ind. J. Rad. Spa. Phys.,23, 157-164, 1994.

Whitney, H. E., Aarons, J., and Malik, C.: A proposed index for measuring ionospheric scintillations, Planet. Space Sci.,17, 1069-1073, 1969.

Woodman, R. F. and LaHoz, C.: Radar observations of equatorial F-region irregularities, J. Geophys. Res.81, 5447-5466, 1976. 